\title{
OS NEWEN NOS PROCESSOS POLÍTICOS DE PRODUÇÃO E SOCIALIZAÇÃO DE CONHECIMENTOS-ONTOLOGIAS
}

Ana Margarita Ramos - IIDyPCa-CONICET-UNRN

María Emília Sabatella (IIDyPCa-CONICET-UNRN

\section{INTRODUÇÃO}

Desde 2002, em diferentes localidades da província de Chubut, na Patagônia argentina, vem se realizando uma série de Futa Trawün (parlamentos), com a participação de representantes de distintas comunidades e organizações mapuche-tehuelche da região . Esses encontros, exclusivamente indígenas, reúnem membros de organizações e comunidades muito distantes entre si, com o objetivo de compartilhar conflitos, denúncias, demandas, projetos e estratégias de luta conjunta.

Nosso interesse, ao pensar sobre as trocas e pronunciamentos que têm lugar nos parlamentos, reside, por um lado, no fato de eles se inscreverem em uma epistemologia entendida como mapuche-tehuelche, e, por outro, no modo como o conhecimento-ontologia é ali reatualizado como uma prática política. Portanto, consideramos que o Futa Trawün é um interessante ponto de partida para levar a cabo a reflexão proposta por esta publicação, acerca da relação entre os processos políticos e outras formas epistêmicas de entender a política.

Em seu trabalho La Propuesta Cosmopolítica (2005), Isabelle Stengers sugere que diminuamos a velocidade de nosso raciocínio, atentando para as respostas em potencial para as quais ainda não existem perguntas, para as práticas e discursos que ainda carecem de definição e reconhecimento, e para as subjetividades que permanecem nas sombras, sem vozes audíveis. Ela convida os pesquisadores a deter o curso do pensamento habitual, com vistas a elaborar novos conceitos, ou retornar àqueles já conhecidos, mas desde os pontos de vista dos sujeitos que não foram tomados em conta. Nessa direção, é nosso objetivo refletir sobre os processos de atualização e produção de conhecimentosontologias entre aqueles que se definem como mapuche-tehuelche "em luta", especificamente, sobre o modo como são ressignificadas, nesses processos, as próprias noções de conhecimento e de política que costumamos utilizar para compreendê-los. No marco das epistemologias hegemônicas, a colocação em cena desses conhecimentos costuma ser avaliada como estratégia de visibilização diante de uma audiência não indígena (invenção), como um simbolismo ad hoc nas práticas políticas (excessos) ou como meras crenças que tornam peculiar um movimento que, precisamente em razão delas, costuma-se denominar "étnico" (exotismo). Seguindo as reflexões de Marisol de la Cadena (2008, 2010), 
essas formas de nominar as práticas políticas indígenas são resultado dos processos de inclusão e exclusão levados a cabo por certas hegemonias epistêmicas - especificamente aquelas denominadas modernas.

Como ponto de partida, consideremos as definições que Mario Blaser (2009) utiliza para introduzir uma noção geral de ontologia. Por um lado, a ontologia é o inventário das distintas classes de seres e de suas relações; por outro, posto que as ontologias realizam-se em mundos (por meio das práticas de humanos e não-humanos, e de suas interações), ontologias e mundos podem ser entendidos como sinônimos; finalmente, as ontologias seriam também os relatos que dão conta das coisas e as relações que constituem um determinado mundo, e que, portanto, permitem que tais mundos sejam apreendidos. A partir de um ângulo similar, Pablo Wright sustenta que a dimensão ontológica é aquela para a qual "o ser aparece como um campo constituído pela totalidade de suas associações e nexos existenciais, que unem ou permitem a emergência de seres, objetos e eventos discretos" (2007: 2). Dessas definições, destacamos os aspectos afetivos (localizados no nível das experiências) e cognitivos (as reflexões epistêmicas sobre os processos de produção de conhecimento). Portanto, a ontologia é o conhecimento produzido a partir da experiência - histórica, contextual, afetiva e política - de "estar no mundo". Especificamente, o conhecimento-ontologia é aquele saber mais geral que constitui a base e os limites nos quais podemos inscrever o que entendemos como real ou irreal, como óbvio ou extraordinário, como possível ou impossível.

Focalizando a Amazônia, alguns autores convidaram-nos desde cedo a refletir sobre as questões que as cosmologias ameríndias colocam para os fundamentos ontológicos do pensamento no Ocidente (Descola, 1994; Viveiros de Castro, 1998). Um dos principais aportes dessa concepção perspectivista foi a discussão em torno da noção hegemônica e contemporânea de multiculturalismo, posto que, ao admitir a multiplicidade de culturas, pressupondo a unicidade natural, essa noção não levou em conta o fato de que, a partir de outras construções de mundo, pode existir unidade entre humanos e não-humanos dotados de pontos de vista, emoções e intencionalidade sobre uma diversidade de naturezas e corpos (multinaturalismo). Nessa mesma tradição, outros autores interrogaram as visões específicas em torno, por um lado, do que nós chamaríamos natureza, tempo, história, agência, território; e, por outro, do modo pelo qual certas lógicas de pensamento e ordenamento (como as distinções e as relações hierárquicas) podem ser substituídas por outras (como a apropriação/canibalismo e as conexões sem pontos hierárquicos de referência); finalmente, também se tem atentado para as redefinições de natureza e cultura na definição dos vínculos sociais e de parentesco .

Esse caráter deslocador que teriam os conhecimentos não hegemônicos reside no fato de que, ao serem objetivados como lugares de enunciação para apelos e demandas, podem, em certas ocasiões, questionar o próprio “contrato moderno" (Latour, 2007), razão pela qual foram, em dado momento, desqualificados como leituras legítimas da realidade. Os marcos de interpretação que questionam a divisão fundante da modernidade (entre natureza e cultura) e as classificações que dela derivam (ciência, crenças e política) produzem subjetividades políticas que, nos casos em que logram ser vistas e ouvidas, deslocam as zonas conceituais confortáveis. Essas subjetividades podem se revelar "incômodas", já que produzem e são produzidas por "uma insurgência de forças e práticas indígenas com a capacidade de desestabilizar de modo significativo as formações políticas predominantes e reorganizar os antagonismos hegemônicos" (De la Cadena, 2008: 142). Ou, nas palavras de Jacques Rancière (1996), instala um conflito onde não 
existia, ao desvelar a incomensurabilidade existente entre as formas hegemônicas de categorizar, ordenar, nominar, e as lógicas que, quando exigem ser levadas a sério, introduzem enunciações e práticas que obrigam a considerar os que não vinham sendo incluídos ou nomeados. A relação entre ontologias e processos políticos foi considerada, então, colocando-se ênfase no potencial das primeiras para expor uma distorção nos direitos de presença e para confrontar a obviedade das diferenças (Amin, 2002) estabelecidas nos marcos epistêmicos hegemônicos. Nesta linha, alguns autores (De la Cadena, 2008, 2010; Escobar, 2005) propuseram que tensionássemos as próprias categorias modernas de "política" e suas dimensões colocadas em jogo nas negociações:

'[...] no momento político em que se criou a divisão ontológica entre humanos e natureza, também se firmou uma divisão para hierarquizar outros mundos socionaturais e se estabeleceu a criação da política como um fato humano diferente da natureza, que foi destinada à representação científica. Visto desde esse plano histórico distinto - revelando a política epistêmica das políticas modernas -, o conflito potencialmente mudaria: mais que um problema cultural entre o progresso universal e as crenças locais, o destino de seres não-humanos emergiria como um conflito político entre mundos, um deles demandando desacordo simétrico. Nesse ponto, a política não estaria composta apenas de relações de poder e antagonismos silenciados - mas seria 'formada por relações entre mundos"' (De la Cadena, 2010: 352).

Seguindo essas perspectivas, entendemos que as ontologias sempre são políticas. Como explica Blaser(2009), elas o são quando implicam um sentido amplo da política, envolvendo as práticas que modelam mundos particulares, mas também quando se referem a uma área de estudo centrada em lutas e conflitos que advêm como diferentes mundos ou ontologias esforçando-se para seguir existindo, assim como para interagir com outros mundos.

No marco destas considerações teóricas, organizamos nossas reflexões em torno dos seguintes eixos: a) a justaposição que os próprios atores mapuche-tehuelche, autodenominados como "estando em luta", reivindicam entre projeto político e produção de conhecimento-ontologia na própria definição do Futa Trawün; b) a realização das ontologias por meio das práticas de humanos e não-humanos, e de suas interações; e o modo pelo qual essas ontologias constituem e são constituídas por determinadas lutas sociopolíticas e históricas.

\section{A PRODUÇÃO DE CONHECIMENTO COMO PROJETO POLÍTICO}

Dois anos atrás, nossa equipe de pesquisa iniciou uma série de encontros com o objetivo de repensar os modelos epistêmicos utilizados para entender os processos históricos dos grupos mapuche e tehuelche. Ao longo dessas discussões, das quais participaram também alguns mapuche-tehuelche, reconhecemos como nosso principal desafio encontrar marcos de interpretação que permitissem recuperar os sentidos com os quais as experiências do passado haviam sido transmitidas na memória social. Em certa ocasião, quando tínhamos que assinar um trabalho em coautoria, um dos militantes mapuche que contribuíra com o texto, solicitou ser formalmente apresentado como "mapunche". A esse respeito, e no contexto das discussões que vínhamos desenvolvendo, ele explicou sua decisão da seguinte maneira: “"Mapunche'é um adjetivo, não é uma categoria étnica como 'mapuche'. 'Mapunche' enfatiza meu processo de formação no conhecimento mapuche como um processo permanente, me descreve como percorrendo o caminho ao encontro da minha subjetividade como mapuche" (Cañumil, comunicação pessoal, 2011). 
Muitos dos mapuche com os quais temos conversado ao longo destes anos costumam colocar a mesma ênfase nas noções de subjetividade e de processo para explicar a ideia de conhecimento. Um processo que geralmente é contado como uma história pessoal e grupal de relações, conexões e trocas.

O marco filosófico que costuma estar pressuposto nessas explicações advém de uma forma de entender o wallontumapu (universo ou mundo). O wallontumapu inclui tanto o mundo externo (por exemplo, os astros, o céu, a terra, os animais), como o universo interno da subjetividade (um mundo que as pessoas podem perceber, por exemplo, através dos sonhos ou através das mensagens das pulsações do corpo). Os seres (ngen) que estão nos elementos do wallontumapu (universo externo e interno) possuem newen, isto é, a energia ou a força percebida pelos sentidos, ou através dos pewma (sonhos), witan (pulsações do corpo), perimontu (visões).

'Primeiro percebemos o newen e, através dessa percepção, chegamos ao ngen [fonte do conhecimento], que nos dá o kimün [conhecimento] sobre tudo o que existe e suas relações (incluindo a si próprio). A habilidade para perceber a energia do newen e, por meio dela, poder identificar o ngen demanda um modo de conhecer no qual tudo o que existe no entorno, incluindo os seres humanos, participa como agente na tarefa de produzir conhecimentos" (Cañumil, comunicação pessoal, 2011).

Destacamos, então, três características centrais na concepção do conhecimento mapuche. Em primeiro lugar, o conhecimento ou kimün é antes uma complexa série de conexões e relações entre elementos do universo, que definições referenciais sobre entidades isoladas. Em segundo, as experiências de mundos (conhecimentos-ontologias) necessariamente são diferentes, posto que são resultado de processos de socialização e transmissão (ngulantuwün), a partir dos quais as pessoas adquirem distintas habilidades (kimlu) para se vincular com certos newen do universo (wallontumapu) e interpretar suas mensagens. Não há forma de produzir conhecimento que não seja através da socialização, entendida em um sentido amplo, como um diálogo entre pessoas, ngen e antepassados. $\mathrm{O}$ fato de o conhecimento ser mais uma habilidade adquirida que um conteúdo expressa-se em frases socioculturalmente significativas como "temos um dom porque escutamos bem". O kimün (conhecimento) e o kimlu (dom/habilidade) são o resultado de perceber, conversar e pensar sobre "tudo o que existe", em contextos de socialização. Finalmente, posto que o kimün não pode ser entendido fora dos contextos de transmissão nos quais é atualizado, retransmitido e ressignificado, ele só pode ser definido como um permanente devir. De acordo com Pablo Cañumil (Cañumil e Ramos, 2011), o conhecimento repousa em todos os pontos do universo, mas reconhecê-lo como tal depende de nossa capacidade de percebê-lo, falar com ele, socializá-lo e incorporá-lo em nossa subjetividade. E as possibilidades de que esse reconhecimento ocorra dependem dos contextos históricos nos quais foram levadas a cabo essas conversas.

O propósito deste trabalho é levar em conta essa episteme - centrada nas relações entre todos os elementos do universo (incluindo os humanos) - para pensar suas implicações políticas. Na província de Chubut, quando indivíduos mapuche-tehuelche narram suas biografias como histórias de luta por seus direitos, geralmente mencionam os parlamentos ou Futa Trawün como uma das instâncias centrais de socialização de um kimün especificamente mapuche. Nesses encontros, não só se aprende, mas também se participa da própria produção de conhecimento. 
Os Futa Trawün foram descritos pelos cronistas e viajantes que exploraram a Patagônia a partir do século XIX. Tais descrições enfatizam a participação de grupos de parentesco mapuche-tehuelche de pontos geográficos distantes, assim como a força política das decisões coletivas tomadas ali. Na província de Chubut, no ano de 2002, a Organização Mapuche Tehuelche 11 de Outubro toma a iniciativa de retomar essa prática política, que havia sido realizada de forma esporádica e autônoma ao menos até o início do século XX. Convocados pelos próprios grupos indígenas, os parlamentos atuais são encontros políticos nos quais os mapuche-tehuelche pensam estratégias de ação e de luta para serem levadas a cabo coletivamente em face da arbitrariedade de certas políticas indigenistas estatais, de projetos extrativistas governamentais e privados (minerários, florestais e petrolíferos) e da expropriação territorial realizada por latifundiários e pelo Estado. Os parlamentos costumam durar dois ou três dias e são realizados alternadamente em localidades que estejam atravessando situações de conflito. Ao longo das reuniões, as discussões sobre o contexto político em que se encontram inseridos são intercaladas com momentos que podem ser definidos como espirituais (orações, cantos sagrados) e de produção de conhecimento (atualização de memórias grupais e de experiências pessoais do passado, compartilhamento de definição de conceitos, de modos apropriados de realizar certas práticas e performances). A conjuntura sociopolítica de 2002, quando se decide reconstruir essa prática ancestral, poderia ser caracterizada mencionando-se o avanço da propriedade privada sobre os territórios indígenas, a crescente judicialização e criminalização da mobilização indígena em face desse avanço, e a progressiva percepção do tratamento assimétrico nas ações que vinham sendo realizadas pelas vias legal e administrativa.

Nossa aposta aqui consiste em considerar os parlamentos como um dos elos da cadeia de socialização e transmissão de conhecimentos, no qual as relações entre as dimensões políticas da troca e da produção de saberes tornam-se notórias para os próprios participantes. Desde os primeiros pronunciamentos emitidos nos parlamentos, a produção de conhecimento tem sido reconhecida como um dos eixos centrais da militância indígena:

"Esta instância de debate e troca de conhecimentos foi recuperada por nosso povo nesta região após mais de um século de ocupação por parte do Estado argentino [...]. No resgate e desenvolvimento de nossa espiritualidade encontramos o fundamento de nossa luta e garantimos o cumprimento de nossos objetivos" (I Parlamento, 2003, Vuelta del Río).

A prática de se reunir em parlamento, entendida como uma troca, busca articular conhecimentos com estratégias políticas e, nesse processo, recupera uma epistemologia centrada nas conexões entre os elementos do universo, a transmissão (ngulantuwün) de habilidades (kimlu) para estabelecer essas conexões, e o permanente devir em torno do que se entende como conhecimento próprio. Em uma cerimônia realizada no marco de um Futa Trawün, um dos participantes observou:

'Hoje esta cerimônia adquiriu uma importância particular: o fato de cada comunidade, organização, família ter esse conhecimento [sobre a cerimônia] significa que a relação do nosso povo com todos os elementos ou newen [forças] que são parte do universo ainda existe" (Loma del Tero, Esquel, 2003).

Perguntamo-nos, então, de que maneira é entendida a política - ou, para usar uma expressão nativa, o “estar 
em luta" -, quando se considera que "ter conhecimento" é evidência de um tipo diferente de relação entre o povo Mapuche-Tehuelche e os elementos do universo. Nas próximas seções nos centraremos na mútua imbricação entre conhecimento e política - na qual explicitamente se inscrevem os parlamentos -, com vistas a dar conta das formas pelas quais os conhecimentos-ontologias são produzidos relacionalmente (ngulantuwün) e atualizam relações (no wallontumapu) como parte do fazer político.

\section{OS NEWEN: FORÇAS E AGENCIAS}

\section{O NEWEN DA FACA}

Vinte anos atrás, o discurso oficial e o senso comum sustentavam que na província de Chubut não havia indígenas, posto que eram poucos e, em sua maioria, estrangeiros oriundos do Chile. Diante da falta de terras férteis disponíveis, intensificou-se o processo migratório das zonas rurais para as urbanas, em busca de trabalho remunerado, fazendo crescer demograficamente os bairros marginais das principais cidades da região. Simultaneamente, continuava o processo de expropriação do território indígena, iniciado no final do século XIX pelas campanhas militares do Estado argentino contra a população indígena, e aprofundado com o avanço da propriedade privada. A partir de 1990, algumas iniciativas indígenas da província começam a tornar visível essa negação hegemônica, desencadeando um processo de recuperação de territórios, de revalorização de seus conhecimentos e de fortalecimento de alianças e de solidariedade entre aqueles que se reconheciam indígenas. No início do século XXI, a província de Chubut surpreendia os analistas políticos com uma das porcentagens mais altas de autoidentificação indígena no censo nacional. Nesse contexto, os parlamentos mapuche-tehuelche reúnem pessoas com trajetórias sociais diferentes: algumas viveram a vida toda nas cidades, outras em fazendas, e outras ainda nas terras que herdaram de seus antepassados; algumas chegam preocupadas com a suspensão de algum subsídio estatal e outras, havendo militado na causa indígena já há vários anos; algumas se apresentam como lonkos (chefes) de determinadas comunidades indígenas e outras vêm de localidades rurais dispersas, sem reconhecer seu pertencimento a qualquer comunidade em particular. Tendo em conta essa heterogeneidade de contextos de socialização, chama a atenção o fato de os participantes dos parlamentos encontrarem prontamente signos comuns para atualizar marcos epistêmicos compartilhados. A esse respeito, descrevemos aqui como o uso cerimonial de uma faca pôde reunir distintas histórias de kimlu (habilidades) e kimün (conhecimentos) em um marco afetivo de interpretação da realidade.

Dentre as pessoas que vêm se encontrando nos parlamentos mapuche-tehuelche realizados em Chubut, tomemos a história do lonko Huenullan, chefe de uma das comunidades rurais da província. Huenullan lembra que era muito jovem quando recebeu uma perimontu (visão). Um dia, estava pastoreando as ovelhas e se deitou em um outeiro: "parecia que tinha adormecido, mas não... vi três seres, levantadinhos assim, do jeito como anda o kalfumalen [menina que carrega a bandeira na cerimônia religiosa do camaruco ], com essas roupas azuis, eu vi direitinho". Huenullan conta-nos que compartilhou essa visão com sua mãe e que foi ela quem interpretou a força daqueles newen como mensageiros de sua missão neste mundo: "vai fazer camaruco". Huenullan e sua mãe realizaram o camaruco anualmente durante aproximadamente uma década. Com a morte dela, ele passou a realizar apenas cerimônias 
domésticas, com seus parentes mais próximos. Contudo, mais de trinta anos depois, sente-se convocado como lonko ou chefe do camaruco nos parlamentos retomados pela Organização 11 de Outubro.

No ano de 2004, Huenullan viaja vários quilômetros com sua família para participar de um parlamento na cidade de Esquel, província de Chubut. Em Loma del Tero, a pouca distância do centro da cidade, à véspera de um julgamento que opunha a empresa Benetton e uma comunidade mapuche, reuniu-se aproximadamente uma centena de pessoas, iniciando o parlamento com um nguillatun (reza mapuche). Daquela colina suave e arborizada, via-se abaixo a cidade de Esquel, suas ruas e seu movimento. Um lonko que vivia na cidade conduziu a cerimônia, mas outros/as lonko de diferentes lugares, como Huenullan, ofereceram-se para presidir a reza conjuntamente. Arazão desse encontro era "apoiar Atilio Curiñanco e Rosa Nahuelquir", que estavam sendo acusados judicialmente de invasores, por haverem recuperado terras em disputa com a Companhia de Terras do Sul Argentino (hoje pertencente à Benetton).

Concluídos os atos rituais diante dos bambus e bandeiras do rewe(altar) que havia sido levantadoali, começaram os discursos finais dos participantes. Homens e mulheres foram tomando a palavra para explicitar o que havia ocorrido: ao longo da reza, haviam compartido com Rosa e Atilio seus respectivos newen (forças do entorno de seus lugares de origem). Além disso, ao tomar a palavra, cada um dos oradores compartilhou com os demais a história particular de suas resistências e conflitos, e das experiências de luta que estavam ocorrendo em suas comunidades ou localidades (umas distantes das outras). Em meio a discursos de encorajamento, avaliaram também o alcance da luta empreendida, compartilhando sua determinação: estavam “dispostos a chegar até as últimas consequências”. No contexto dessa troca cerimonial, uma das werken (mensageiras) de uma comunidade rural intervém para dizer o seguinte:

'Nós estamos diante do Estado, nós somos protagonistas de toda essa história e somos como as plantas, como as árvores, porque nascemos nestes lugares e ninguém vai arrancar nossas raízes, com isso perderíamos nosso rakizuam [pensamento], nossa forma de nos organizarmos... e nossa identidade como povo, também quero pedir aqui ao irmão [referindo-se ao lonko Huenullan] que com sua faca de prata transmita a força de que Atilio necessita... E os anciões aqui presentes sabem perfeitamente a que me refiro...".

Após esse pedido especial, cujos sentidos são pressupostos, porque os presentes "sabem" de que se trata, Huenullan toma sua faca de prata e diz:

“Bom, com licença, então. [Aproxima-se com a faca de Rosa e Atilio.] Que vocês tenham muita força com isso, essa é a força que eu tenho, vai ajudar muito vocês, que tenham muita força com suas terras, e vão ganhar, não vão perder. Resistência, irmão, se vocês lutarem como nós - que viemos aqui e que estamos lutando -, terão muita sorte, e não vão perder as terras, não vão perder"'.

A força de seus antepassados e do entorno de que ele provém materializa-se na faca. O newen de sua faca é sua própria história, são suas habilidades (kimlu) e conhecimentos (kimün), são as relações com o universo que ele herdou de seus antepassados por meio de visões e sonhos. Esse ato produz o canto, expressões de alento ("não chore, irmã", 
"não vão ferrar vocês") e os gritos (afafan) que os participantes compartilham para expressar sua força conjunta. Com esse reconhecimento, o evento aprofunda seu próprio marco de interpretação, no qual os conhecimentos-ontologias experimentados como próprios passam a ser aquilo que confere sentido a tudo o que é dito e representado ali.

Um dos militantes mapuche da 11 de Outubro então comenta: “este encontro não é financiado por ninguém, por nenhum partido político, nem pelo Estado... não estamos aqui para criticar nossa marginalidade, estamos aqui para ganhar [gritos afafan]". O evento se transforma, as pessoas se juntam e começam a interagir, conversando em mapuzügun(línguamapuche) e encorajandoumas às outras. Essas intervenções pessoais são rapidamenteinterrompidas pelo lonko oficiante da cerimônia:

'Eu vou falar algumas coisas. Somos mapuches, somos os donos da terra, somos os filhos nativos desta mãe terra querida, os mapuche, os tehuelche, todos somos da terra, não temos por que fraquejar. Aconteça o que acontecer, vamos seguir adiante, temos braços bons, temos a cabeça boa para pensar, temos pés para caminhar, por isso não temos que desistir, ninguém, nem as mulheres, nem os homens, temos que ser um, e demonstrar isso, como mapuche, como tehuelche [... . Os brancos têm que nos deixar em paz, a nós, os mapuche, nós temos direito à terra, nós não andamos em terra alheia, nós pisamos a nossa terra, somos seus werken [mensageiros], e é isso, irmãos, obrigada...”.

As pessoas tornam a emitir os gritos do afafan, algumas também se expressam dizendo "feley" (que assim seja). Nesse dia, depois de descer da Loma del Tero, continuaram o parlamento na cidade de Esquel, para planejar conjuntamente estratégias políticas de curto e longo prazo, em torno das lutas que cada um deles vinha travando em suas respectivas localidades. Conversando conosco, Huenullan disse que nunca perderia seu kimün e que até o último dia de sua vida o levaria consigo e o compartilharia onde fosse preciso: "é uma felicidade para mim, sim, o piuke [coração] se alegra quando faço isso".

Nesse mesmo ano, alguns meses depois, Huenullan torna a viajar com sua família, desta vez para participar do IV Futa Trawün, realizado na localidade de San Martín, também na província de Chubut. Na manhã do segundo dia, tem lugar uma pequena reza, e Huenullan desembainha sua faca e toma a palavra:

'Bom, vou falar algumas palavras... os brancos estão tomando nosso ouro, estão roubando o ouro de nós, estão roubando as minas que nós temos. Nós não mandamos. Agora, nós temos que ganhar... Irmãos, irmãs, escutem-me por favor, todos, todos me escutem, é isso que estamos fazendo aqui, assim vamos ter força, nós teremos os newen que nos deixaram e vamos vencer todos os que estão roubando as coisas [...], é isso, irmãos, muito obrigada, irmãs".

Depois dos gritos afafan e feley, Atilio Curiñanco, outro participante, tomou a palavra. A trajetória de Atilio é muito diferente da de Huenullan, já que é oriundo da cidade de Esquel, onde por muitos anos foi empregado de um frigorífico. Pouco tempo atrás, Atilio Curiñanco e sua família recuperaram terras e conformaram a comunidade mapuche Santa Rosa, hoje em litígio com a empresa Benetton. A partir dessas experiências, ele comenta: 
'Não posso falar em mapuzügun, mas queria estar presente também, digo isso porque também, em algum momento, talvez, fui me esquecendo da minha cultura; e tive que passar por algo muito especial, para que tomasse uma forte resolução, e assim o fiz. Que lindo, que lindo teria sido sentir, sentir que a nossa cultura existe e que o newen, o newen de que falavam nossos avós está presente, e que os espíritos de nossos avós que tanto sofreram também estão presentes para ensinar e corrigir tudo que nós tenhamos feito de errado. Muitos que têm ascendência mapuche, como eu, já não se aproximam, por vergonha, uma vergonha inculcada pelo winka [o branco]: 'é uma ideia suja e vocês têm que apagála', nos diziam [...]. A potência de nosso pensamento deve estar no povo mapuche e não naquele winka que sempre veio para nos prejudicar [o público o acompanha com um feley] [...]. Tenho muitíssimas, muitíssimas coisas para dizer, e digo com muito ânimo, porque eu senti em algum momento que isso era a força, e eu tenho um fruto dessa força...".

As subjetividades colocadas em jogo nesta cerimônia são tão heterogêneas quanto as trajetórias que ali se reúnem. Huenullan narra a si próprio a partir de uma relação antiga com os newen, ao passo que Curiñanco nos conta sobre o modo pelo qual certas experiências do passado foram iluminadas e reorganizadas quando os newen começaram a interagir com ele ("senti em algum momento que isso era a força, e eu tenho um fruto dessa força...”). Porém, e uma vez reconhecida essa heterogeneidade, a cerimônia em seu conjunto é repleta de pressupostos compartilhados através do discurso explícito, dos gritos afafan e feley, do pranto e da emoção ali investida. A reza termina com as palavras de um dos responsáveis pela convocação do parlamento, que fecha - ao mesmo tempo em que abre - o evento. Suas palavras operam como síntese das bases que foram sendo acordadas no transcurso da cerimônia; bases que serão o lugar de pertencimento e de enunciação para a reivindicação de um projeto político coletivo:

"Apesar de, nesta manhã, termos fechado tudo que tem a ver com nosso kimün [conhecimento] mapuche, com esse contato, como nós dizemos, com cada elemento da natureza, temos ainda algumas horas para aproveitar porque há ainda vários temas para serem tratados. Neste rewe [altar] improvisado estamos nos comprometendo a seguir lutando. E não estamos lutando para agonizar ou para ampliar um pouco a agonia do povo mapuche, pelo contrário: estamos lutando para que algum dia nosso povo torne a se levantar".

Em ambas as ocasiões, o uso cerimonial da faca suscitou uma troca de marco de interpretação e, com essa gestualidade, as formas de fazer política adquirem outras dimensões também. Antes de retomar essa ideia, passemos ao exemplo seguinte.

\section{O NEWEN DA AGUADA}

O século XXI apresentou, para diferentes províncias, sobretudo para aquelas com “recursos propícios" para a exploração, uma forte afluência de projetos minerários, beneficiados pela legislação promulgada na década de 1990 . Tal legislação promoveu a abertura ao capital estrangeiro e ofereceu benefícios para que as empresas estabelecessem empreendimentos produtivos e extrativos no país. No contexto específico da província de Chubut, a chegada de capital e o desenvolvimento de novos projetos minerários ensejaram distintas mobilizações em rechaço. Delas participaram diferentes organizações ambientalistas, associações auto-organizadas de moradores, e comunidades e organizações 
mapuche-tehuelche. Estas últimas começaram a se mobilizar e a emitir comunicados acerca da instalação de empreendimentos minerários em seus territórios e dos modelos de desenvolvimento que eles impunham. Tal processo teve início em 2002, quando, diante da instalação de uma mina de ouro nas proximidades de Esquel, um encontro foi realizado nessa cidade. Como fruto do encontro, deu-se a conhecer o primeiro pronunciamento mapuche-tehuelche da província sobre a mineração:

“...As montanhas e todas as formas de vida ainda têm seu pillan [espírito], e continuamos coexistindo com elas. Nós, a Gente da Terra, como parte do wallontumapu [território: terra, subsolo e céu] entendemos que a violação da Mãe Terra nunca poderá se trocada por uma esmola...” (Esquel, 2002).

Esse primeiro posicionamento em relação à mineração sentou as bases das discussões que se seguiram. No IV Parlamento, realizado anos depois na localidade de San Martín, o debate sobre o tema da mineração iniciou-se com uma discussão em torno da necessidade de dispor de conhecimentos adequados para contrapor os argumentos das empresas mineradoras. Para alguns, fazia-se necessário recorrer aos especialistas para que explicassem, do ponto de vista da ciência, os prejuízos ambientais das atividades extrativas. Nesse contexto, um dos participantes contou que sua avó, nascida na comunidade de Cushamen, costumava aconselhá-lo sobre os modos apropriados de tratar os seres da terra:

"Ela dava esse conselho, cada vez que íamos a uma aguada, onde havia um minador: 'esta aguada tem um dono, um ngen, e você não pode limpar essa aguada com uma pá, ou com algo que a danifique, tem que fazê-lo com suas próprias mãos'. E ela sempre ia e limpava com suas mãos e tirava as raízes para que a água brotasse [... ] porque se eu fizesse isso com uma pá, minha avó me advertia, era muito provável que a aguada secasse”.

Outros participantes confirmaram a importância dessas palavras, compartilhando o modo pelo qual realizavam certas tarefas cotidianas em suas localidades, ou lembrando-se de ter recebido conselhos similares. Um dos lonko acrescentou que as empresas mineradoras escavavam a terra como os piche (espécie de tatu), matando e destruindo os newen. A partir desse intercâmbio, e depois de acordar que esses conselhos poderiam ser traduzidos "a um rio, a um menuco (mallín), a uma montanha”, permitindo prever os danos que as mineradoras provocariam, chegou-se à conclusão que não importava se para o resto da sociedade esses saberes não eram conhecimento científico, posto que para os mapuche se tratava de saber indubitavelmente especializado.

Em seguida, acordou-senão apenas queera desnecessário recorreraos cientistas para contraporargumentos, mas também que não era preciso falar em mineração e ecologia quando se reunissem com os mapuche e tehuelche de outros lugares. Para conscientizar os indígenas sobre os danos que seriam causados pela mineração em suas comunidades, optou-se por um modo de atuação diferente daquele dos ambientalistas: era suficiente chegar às zonas afetadas para falar "do pensamento e da cosmovisão do povo mapuche", já que "dentro dessas experiências compartilhadas todos entendemos como a exploração minerária afeta nossa mapu [terra]". 
Em seguida, foram identificados conjuntamente os pontos centrais de discordância:

“O governo diz que o Estado é o dono do céu e do subsolo, é o que eles dizem, não? [...]. O espaço territorial do mapuche, o que é? É a terra que voa, é a superfície, é o subsolo, é todo o nosso entorno, digamos [...]. Ou seja, tudo isso está dentro de nossa lógica e de nosso pensamento como mapuche".

'[...] também temos que começar a enfatizar, irmãos, quando falamos de recursos: o que são os 'recursos naturais'? O que isso quer dizer? Isso tem a ver com cada elemento que nós estamos permanentemente nomeando, como os mencionamos hoje na cerimônia do nguillatun... Uma aguada para o winka [não mapuche] é um recurso; para nós, para nós, os mapuche, é mais um elemento da natureza, que tem seu nome, que tem seu dono, que tem uma relação direta conosco [...]. Para o winka são recursos naturais, para nós são newen”.

Nessas intervenções, assim como em outras, os conflitos são evidenciados como traduções equivocadas, de modo a inscrever as lutas pelo território e pela autodeterminação em uma disputa epistêmica, em que os modos de existência, caracterizados como dissímiles, são postos em tensão. Por um lado, território nomeia o espaço do ar ao subsolo, e não uma “mera porção da superfície da terra", e, como consequência dessa espacialidade, "nem as cercas de arame, nem os títulos de propriedade podem solucionar o problema com a mineração". Por outro lado, os elementos do entorno não são "recursos naturais", mas têm seu nome, seu dono e uma relação com os humanos. Emúltima instância, essas formas de presença pressupõem outros modos de ver o mundo, nos quais o próprio modelo de exploração e desenvolvimento hegemônico é posto em questão:

'Reafirmamos nossa oposição à exploração minerária em território mapuche... Esta resposta que articulamos como expressão do povo Mapuche não se limita à discussão sobre tal ou qual porcentagem de participação nos lucros, nem em supostas condições mais sustentáveis de exploração. Surge de nosso kimün, quer dizer, do nosso conhecimento mais profundo. Respeitamos e defendemos os newen das montanhas e todos os demais newen. Nós vemos o universo de outra maneira: não se pode matá-lo, não se pode contaminá-lo. Prejudicar os newen é atentar contra nossa cultura, nossa identidade" (III Parlamento, Prane, 2004).

Como sustenta Stengers(2005), nesses conhecimentos-ontologias que os parlamentos atualizam, os “invisíveis" são convocados e consultados (o pillan da montanha, os newen da aguada, os ngen do subsolo, da terra e do ar), eles são presentificados com o objetivo de impedir qualquer atalho ou simplificação, qualquer diferenciação a priori entre aqueles que contam e aqueles que não. Os newen são ameaçados e, com eles, o che (gente) - "se permitirmos que tirem os minerais de nossa mapu, destruirão os newen e prejudicarão a relação que existe entre todos eles, e entre todos eles e o che. . isso colocaria em risco nossa existência e nosso devir como povo" (Encontro em Gan Gan, 2011). Portanto, os mapuche convidam os tomadores de decisões (especialistas do Estado ou das empresas privadas) a pensar duas vezes ou, ao menos, a tomarem ciência da possibilidade de que o newen da aguada, entre outros, também seja um agente político nas negociações em curso. 
No amplo leque de práticas e discursos que produzem conhecimento compartilhado, a seleção daqueles centrados nos newen responde a seu poder de síntese para entender as duas dimensões principais nas quais os conhecimentos-ontologias e as formas de fazer política confluem. Em abstrato, os newen são os mediadores para adquirir habilidades (kimlu) e conhecimentos (kimün) sobre o universo (wallontumapu), mas, à medida que estão situados em entornos específicos, são o meio através do qual as pessoas adquirem um conhecimento igualmente específico e situado. Esse conhecimento particular é entendido como uma força que as pessoas carregam consigo, a força de suas histórias de relação com os seres humanos e não-humanos de seu entorno, a força de seus lugares de origem, que pode ser compartilhada, por exemplo, por meio da faca em que se materializa. Mas os newen também são agentes, intervêm nos processos históricos por meio de suas mensagens e de suas ações. O newen da aguada, por exemplo, é um dos principais agentes no momento de negociar uma posição a respeito da mineração.

\section{CONSIDERAÇÕES FINAIS: PONTOS DE ENCONTRO ENTRE ONTOLOGIAS E POLÍTICAS}

A ontologia é política porque os mundos possíveis são atualizados e recriados em contextos de luta, e porque as formas pelas quais um conhecimento-ontologia é objetivado têm poder performativo em relação a esses contextos. Ao mesmo tempo, a política é ontológica porque o fundamento desde o qual se define o próprio campo da política (em relação com os modos de existência de humanos e não-humanos) é ontológico, e porque o próprio fazer político implica embarcar em lutas que também são epistêmicas.

No marco dessas relações, propusemo-nos a pensar sobre as formas de fazer política e produzir conhecimentoontologia em contextos etnográficos específicos, os parlamentos mapuche-tehuelche da província de Chubut, na primeira década do século XXI, em uma conjuntura definida pela ameaça do avanço da propriedade privada e das mineradoras.

Seguindo essa proposta, começamos por entender que as habilidades e conhecimentos são produzidos ao longo da vida. Esses processos permanentes de diálogo - com outros humanos e com os newen - adquirem sua especificidade das situações e entornos nos quais as pessoas se relacionam. Assim como Huenullan, quando os newen apareceram-lhe em uma visão (perimontu), interpretou que sua missão era ser lonko, Curiñanco lamentava não ter sentido antes a presença dos newen e dos espíritos de seus antepassados para aprender com eles. Como explicava Pablo Cañumil (ver seção 2), o conhecimento sobre tudo o que existe e suas relações (incluído o próprio sujeito) vai sendo produzido à medida que os newen são percebidos. Os elementos do universo, através de suas energias ou forças, expressam-se em sinais físicos, sonhos ou visões, e a habilidade para percebê-los e escutá-los é o ponto de partida da epistemologia mapuche. Aqui pretendemos enfatizar menos a compreensão da experiência de perceber os newen, que o fato de Huenullan e Curiñanco deterem a velocidade de seus raciocínios habituais para considerar seriamente quais as consequências epistemológicas e políticas dessas consultas e intervenções em suas vidas.

Mas as ontologias não são apenas produzidas em mundos particulares (através das práticas de humanos e não-humanos, e de suas interações); os conhecimentos-ontologias também se realizam através dos discursos que, ao 
dar conta das coisas e das relações que constituem um determinado mundo, tornam-no apreensível. Desse ângulo, o Futa Trawün é um espaço privilegiado de socialização de relatos para encontrar modos de tornar o mundo apreensível nas conjunturas do presente. O parlamento reúne as pessoas pressupondo a experiência comum de "estar em luta" ("temos que ser um, e demonstrar isso, como mapuche, como tehuelche"), e, consequentemente, articula os relatos autobiográficos sobre os mundos a partir dessa perspectiva em particular. Nessa direção, o Futa Trawün encerra uma subjetividade política, a partir de um tipo de relação específica entre humanos e outras formas de vida. Os parlamentos são âmbitos de compartilhamento de conhecimentos pressupostos nas práticas ("sabem perfeitamente a que me refiro...", dito por uma mulher depois de pedir a Huenullan que compartilhasse seu newen através de sua faca) ou explícitos nos discursos, como no relato dos conselhos da avó sobre como deveriam ser tratados os newen das aguadas. Na socialização desses saberes durante os parlamentos, pessoas que não se conhecem ou que vivem distantes umas das outras produzem em conjunto os sentidos ontológicos e conjunturais da experiência de ser "gente da terra" (mapuche).

No Futa Trawün, essa instância de ngulantuwün (transmissão), que a epistemologia mapuche-tehuelche reconhece como central na produção do conhecimento, também se inscreve em um contexto de diálogo com os discursos hegemônicos proferidos por funcionários do governo ou empresários. A partir do momento em que certas formas de nomear e de argumentar são identificadas como antagônicas, a tarefa de produzir conhecimento próprio dá-se em diálogo com elas. Nesse sentido, a ênfase na seleção e organização das experiências é uma resposta às formas hegemônicas de categorizar e ordenar, e, na confrontação, seu valor performativo central consiste em revelar a incomensurabilidade das duas lógicas (como a controvérsia entre entender a aguada como um recurso natural ou como um ngen). Dentre todas as experiências possíveis e todos os saberes herdados e plausíveis de serem objetivados, ganharão relevância aqueles que permitam reconhecer e entender o litígio. A síntese do debate em pronunciamentos escritos destinados a um público mais amplo implica outros desafios de comunicação. Neste caso, revela-se o modo pelo qual os conhecimentos ancorados no afeto articulam-se em formações discursivas de aboriginalidade (Briones, 1998), produto de lutas indígenas que se prolongam no tempo e no espaço. Nessas formações hegemônicas de aboriginalidade, alguns conhecimentos-ontologias adquiriram autonomia em relação a seus contextos de produção e, através da literatura, dos filmes, das etnografias e da circulação digital de comunicados públicos produzidos por ambientalistas ou indígenas de distintos lugares, converteram-se em textos padronizados, disponíveis para serem utilizados e com a vantagem comunicacional de serem compreensíveis para a grande maioria das pessoas.

A produção dos conhecimentos-ontologias é histórica e contextual em todos esses níveis de ngulantuwün (socialização/transmissão): no nível das experiências biográficas e trajetórias grupais, no qual as pessoas interagem com determinados newen, de quem receberão o kimlu e o kimün que as definirão como um tipo de sujeito determinado; no compartilhamento e objetivação dessas experiências a partir das quais os mundos se tornam apreensíveis; no diálogo com os antagonistas reconhecidos como tais e na articulação com formações de aboriginalidade disponíveis. O conhecimento-ontologia não é um saber que se transpõe quase igual a si mesmo em distintos lugares, posto que em cada contexto particular é o resultado de uma negociação específica, na qual os sentidos não são os mesmos, precisamente porque as vozes que intervêm nas definições são heterogêneas, históricas e cambiantes. 
Considerando o que foi dito até aqui, o contexto político intervém como um marco histórico particular nas instâncias de ngulantuwün nas quais a produção de conhecimento-ontologia é negociada. Mas a ontologia é política em outros sentidos mais constitutivos. Voltando a nossos exemplos - os newen da faca e da aguada -, entendemos que essas forças intervêm nas instâncias de ngulantuwün com vozes e ações significativas que lhes são próprias. Como argumenta Stengers, "a arena política está habitada pelas sombras dos que não têm voz política, não podem ou não querem tê-la" (2005: 996). Esse reconhecimento leva-nos a ampliar nosso sentido de política, com o propósito de não deixar de lado as práticas que modelam mundos particulares. Em outras palavras, os usos que Huenullan faz de sua faca não apenas atualizam um mundo particular e compartilhado pelos participantes, mas, fundamentalmente, "trazem" os newen, tornando-os presentes. Essa presença transforma o evento - os discursos, os sentidos do que é dito e as relações entre os participantes - em um acontecimento no qual a consciência de grupo é construída conjunturalmente, a partir dos afetos e sentidos de uma ontologia-mundo. Depois da apresentação de Huenullan, pessoas que não se conheciam ou que haviam se visto poucas vezes antes, compartilharam as forças ou newen de seus respectivos lugares. $\mathrm{Na}$ Loma del Tero, os newen saíram da sombra da arena política, intervindo para o empoderamento dos participantes do parlamento.

Da mesma forma, ao ser mencionado e socializado no parlamento, o newen da aguada - cuja presença no mundo parece não ser questionada pelos participantes - também se desloca das sombras para intervir na arena política com sua agência própria. Os participantes já haviam recebido conselhos similares sobre como tratar as aguadas, porém, no contexto de ngulantuwün, seus donos (ngen) e forças (newen) tornam-se agentes centrais na definição de um posicionamento coletivo diante do avanço das mineradoras.

A ontologia também é política à medida que afirma a existência de um mundo em contradição ou antagonismo com outros mundos. Em certas ocasiões, orientar as decisões políticas a partir dos marcos dos conhecimentos-ontologias pode implicar embarcar em lutas e conflitos que se apresentam como diferentes mundos. Sustentar que uma aguada não 
é um recurso natural passível de ser explorado, mas um newen que tem um nome e um dono (ngen), e com o qual se estabelece uma relação de diálogo e respeito, pode resultar "incômodo" ou mesmo desestabilizador para as formações políticas predominantes. A presença dos newen nas arenas políticas introduz o conflito onde este não existia, ao revelar a incomensurabilidade entre os conhecimentos-ontologias mapuche-tehuelche e as epistemologias hegemônicas, nas quais esses newen não podem ser considerados e nomeados.

Na prática, e como propõe Arturo Escobar, o caráter desordenador da ontologia política não provém da diferença cultural por si só, mas de seus efeitos na "distribuição da predominância cultural e das lutas em torno dela" (2005: 130). Os participantes do parlamento afirmam que se opõem à mineração e que essa posição não se limita à discussão sobre participação nos lucros ou condições sustentáveis de exploração, posto que, desde seu kimün, a única opção é respeitar e defender os newen do wallontumapu. Em afirmações como essa, eles estão desordenando os processos de distribuição cultural - qual perspectiva define as normas e os valores que regulam as práticas sociais - para reverter desigualdades na ordem social.

Nos Futa Trawün, a socialização (ngulantuwün) de habilidades (kimlu) e conhecimentos (kimün) sobre o mundo possibilita leituras da realidade que, sendo inimagináveis para as lógicas modernas, podem se revelar, em seus objetivos, subversivas e insurgentes (Walsh 2005).

Versão em português: DanielaAlarcon

\section{BIBLIOGRAFIA}

AMIN, Ash. "Ethnicity and the multicultural city: living with diversity". Environment and Planning A, 34(6), 2002, pp. 959-980.

BLASER, Mario. 'Political ontology: cultural studies without 'cultures'?’. Cultural Studies, 23(5-6), 2009, pp. 873896.

BRIONES, Claudia. La alteridad del "Cuarto Mundo": una deconstrucción antropológica de la diferencia. Buenos Aires: Ediciones del Sol, 1998.

CAÑUMIL, Pablo; RAMOS, Ana. 'Knowledge transmission through the Renü’. Collaborative Anthropologies, 4(1), 2011, pp. 67-89.

CARSTEN, Janet (org.). Cultures of relatedness: new approaches to the study of kinship. Cambridge: Cambridge University Press, 2000.

DE LA CADENA, Marisol. "Política indígena: un análisis más allá de la política". World Anthropologies Network E-Journal, 4, abr. 2008; pp. 139-171. 
DE LA CADENA, Marisol. "Indigenous cosmopolitics in the Andes: conceptual reflections beyond 'Politics"'. Cultural Anthropology, 25(2), 2010, pp. 334-370.

DELRIO, Walter; RAMOS, Ana. "Reunidos en Füta Trawün: agencias políticas y alianzas identitarias desde los parlamentos mapuche-tehuelche". Actas del VIII Congreso de Antropología Social. Salta: Universidad Nacional de Salta, 2006.

DESCOLA, Philipe. In the society of nature: a native ecology in Amazonia. Cambridge: Cambridge University Press, 1994.

FAUSTO, Carlos; HECKENBERG, Michael (org). Time and memory in Indigenous Amazonia: anthropological perspectives. Gainesville: University Press of Florida, 2007.

ESCOBAR, Arturo. Más allá del Tercer Mundo: globalización y diferencia. Bogotá: Universidad del Cauca, 2005.

GARCÍA HIERRO, Pedro; SURRALLÉS, Alexander (org.). Tierra adentro: territorio indígena y percepción del entorno. Lima: Grupo Internacional de Trabajo de Asuntos Indígenas - IWGIA, 2004.

LATOUR, Bruno. Nunca fuimos modernos: ensayo de antropología simétrica. Buenos Aires: Siglo XXI, 2007.

RAMOS, Ana. 'No reconocemos los límites trazados por las naciones: la construcción del espacio en el Parlamento mapuche-tehuelche". 2004 Meeting of the Latin American Studies Association. Las Vegas: LASA, 2004.

RANCIÈRE, Jacques. El desacuerdo: política y filosofia. Buenos Aires: Ediciones Nueva Visión, 1996.

RUMSEY, Alan; WEINER, James (org.). Emplaced mith: Space, narrative, and knowledge in Aboriginal Australia and Papua New Guinea. Honolulu: University of Hawai'i Press, 2001.

STENGERS, Isabelle. "The cosmopolitical proposal”. In: LATOUR, B.; WEIBEL, P. (org.). Making things public: atmospheres of democracy. Cambridge, MA: MIT Press, 2005, pp. 994-1003.

VIVEIROS DE CASTRO, Eduardo. “Cosmological deixis and Amerindian perspectivism”. Journal of the Royal Anthropological Institute, 4, 1998, pp. 469-488.

WALSH, Catherine. 'Introducción: (re)pensamiento crítico y (de)colinialidad”. In: WALSH, C. (org.). Pensamiento crítico y matriz (de)colonial: reflexiones latino-americanas. Quito: Universidad Andina Simón Bolívar-Abya-Yala, 2005, pp. 15-35.

WRIGHT, Pablo. “Diálogos laterales Qom: antropología y filosofia en la perspectiva postcolonial”. Revista Cultura y Religión, 1, 2007, pp. 1-10. 